\title{
Missing Heroes of Pancreatic Surgery: Reply to Professor Kelemen
}

\author{
Calogero lacono \\ Department of Surgery, Unit of Hepato-Pancreatico-Biliary Surgery, University of Verona Medical School, \\ Verona, Italy
}

I would like to thank Prof. Kelemen for his Letter to the Editor regarding our monographic issue on 'Pancreatic Surgery: Past, Present, and Future' [1]. I totally agree that Prof. Hans G. Beger and Prof. Markus W. Büchler have made tremendous contributions in the field of pancreatic surgery. Besides, I admit that we were not able to include all heroes of pancreatic surgery in the present special issue of the International Association of Surgeons, Gastroenterologists and Oncologists (IASGO). This might be partly because IASGO had not been active enough in Germany in the past. Nevertheless, we are glad to announce that IASGO is gaining more and more strong representation among German colleagues, including Prof. Doris Henne-Bruns at the
University of Ulm. It is noteworthy that we had great pleasure to have had Prof. Beger as a special guest in the IASGO World Congress 2015 in China, where he has presented 2 State-of-the-Art Lectures entitled 'Parenchyma-Sparing Local Resection of Benign Tumors of the Pancreas' and 'Severe Acute Pancreatitis: Causes and Consequences for Treatment'.

As Prof. Kelemen rightly pointed out, Prof. Büchler is undoubtedly a great leader in the field of pancreatic surgery not only in Europe but also throughout the world. IASGO Secretary General, Prof. Kyoichi Takaori, told me that he had productive discussions with Prof. Büchler during the International Symposium on Pancreatic Cancer 2016, which was endorsed by
IASGO, and that they have agreed to have, albeit presently at a personal level, future collaborations. Thus, with the wider international representations of IASGO, we will be able to include more international experts in our future projects. Pancreatic surgery is a matter of great interest and we believe that we will have the opportunity for releasing yet another monographic issue on this intriguing topic including more experts of pancreatic surgery all over the world.

\section{Reference}

1 Kelemen D: Missing Heroes of Pancreatic Surgery. Dig Surg 2017;34:86.

\section{KARGER}

E-Mail karger@karger.com www.karger.com/dsu
(C) 2016 S. Karger AG, Basel

0253-4886/16/0341-0087\$39.50/0
Prof. Calogero Iacono, MD

Department of Surgery, Unit of Hepato-Biliary-Pancreatic Surgery University of Verona Medical School, 'GB Rossi' University Hospital P.le L.A. Scuro, 10, IT-37134 Verona (Italy)

E-Mail Calogero.Iacono@univr.it 